\title{
POLÍTICAS CURRICULARES NA BNCC E O ENSINO DAS CIÊNCIAS DA NATUREZA E SUAS TECNOLOGIAS NO ENSINO MÉDIO
}

\section{CURRICULAR POLICIES IN NCCB AND THE OF SCIENCES EDUCATION AND ITS TECHNOLOGIES IN HIGH SCHOOL}

Marina Silveira Bonacazata SANTOS ${ }^{1}$

Jani Alves da Silva MOREIRA ${ }^{2}$

\begin{abstract}
Resumo: O presente texto tem como objetivo compreender sobre as políticas curriculares para o ensino médio, no que se refere às mudanças ocorridas na área do conhecimento Ciências da Natureza e suas tecnologias no ensino médio. Trata-se de uma pesquisa do tipo documental e bibliográfica no qual a análise se desenvolveu a partir de documentos oficiais e fontes bibliográficas que abordam o tema. O referencial teórico adotado compreende o objeto de análise a partir do contex to histórico de produção das reformas educacionais no país, sobretudo a partir da reforma do Ensino Médio e da aprovação da atual Base Nacional Comum Curricular (BNCC).
\end{abstract}

Palavras-Chave: Políticas Curriculares. Reforma do Ensino Médio. BNCC. Ciências da Natureza e Suas Tecnologias.

Abstract: The present text aims to understand about the curriculum policies for high school, in relation to the changes that have occurred in the area of knowledge of Nature Sciences. It is a documental and bibliographic research through the study and analysis of official documents and bibliographic sources that deal with the subject. The theoretical framework adopted comprises the object of analysis from the historical context of educational reforms in the country, especially from the reform of high school and the approval of the current National Common Curriculum Base (NCCB).

Keywords: Curriculum Policies. High School Reform. NCCB. Natural Sciences and Their Technologies.

\section{Introdução}

\footnotetext{
${ }^{1}$ Graduanda e pesquisadora de Iniciação Científica do Curso de Ciências Biológicas (Licenciatura e Bacharelado) da Universidade Estadual de Maringá (UEM). Integrante do Grupo de Estudos e Pesquisas em Políticas Educacionais, Gestão e Financiamento da Educação (GEPEFI- CNPq). Bolsista CNPq.

${ }^{2}$ Docente Adjunto do Departamento de Teoria e Prática da Educação (DTP) e do Programa de Pós-Graduação em Educação (PPE), da Universidade Estadual de Maringá (UEM). Pós-Doutora em Educação (UFPR) com estágio pós-doutoral na Universidade de Salamanca-Espanha.Líder do Grupo de Estudos e Pesquisa em Políticas Educacionais, Gestão e Financiamento da Educação (GEPEFI). Bolsista Fundação Araucária-FA
} 


\section{HORIZONTES - REVISTA DE EDUCACATO}

O texto tem por finalidade analisar as políticas curriculares para o ensino médio a fim de compreender as consequências das reformas atuais para o ensino das Ciências da Natureza e suas tecnologias. Trata-se de uma pesquisabibliográfica e de análise documental. Para alcançar o proposto, a investigação apresenta uma contextualização histórica sobre as mudanças ocorridas nas políticas curriculares do Ensino Médio, com o olhar voltado para a área das "Ciências da Naturezae suas Tecnologias" a fim de elucidar sobre algumas tensões e conflitos nas politicas educacionais.

O Brasil vivenciou diversas mudanças no âmbito político e econômico que se refletiu em processos de reforma nas políticas educacionais, nomeadamente a partir de 2015, com o impeachment da ex-presidenta Dilma Rousseff (2011-2016). Ao assumir o governo provisório, o ex-presidente Michel Temer efetivou mudanças na equipe de gestão no Ministério da Educação (MEC) que implicou em mudanças na lógica da política educacional que estava em curso. Outra mudança centrou-se na alteração da Lei de Diretrizes da Educação Básica, a Lei $\mathrm{n}^{\circ}$ 9.394/96 por meio da Lei $\mathrm{n}^{\circ} 13.415$ aprovada em 16 de fevereiro de 2017. Essa Lei foi aprovada após a medida provisória $n^{\circ} 746 / 2016$ e outras alterações a serem executadas no currículo do Ensino Médio se modificaram, após a aprovação da Base Nacional Comum Curricular - BNCC, homologado pela Portaria no 1.570 de 21 de dezembro de 2017.

A BNCC é um documento obrigatório que norteará o projeto curricular e pedagógico dos sistemas de ensino da Educação Básica no país, o que significa que as "aprendizagens essenciais" (BRASIL, 2017, p. 07), os conteúdos do conhecimento que todos os alunos devem desenvolver e aprender ao longo da sua formação na educação básicaserão também definidos a partir da BNCC. De acordo com o Ministério da Educação:

Conforme definido na Lei de Diretrizes e Bases da Educação Nacional (LDB, Lei ${ }^{\circ}$ 9.394/1996), a Base deve nortear os currículos dos sistemas e redes de ensino das Unidades Federativas, como também as propostas pedagógicas de todas as escolas públicas e privadas de Educação Infantil, Ensino Fundamental e Ensino Médio, em todo o Brasil (BRASIL, 2018).

O currículo do Ensino Médio será estabelecido de acordo com a BNCC que aprovada no âmbito do Conselho Nacional de Educação (CNE) foi aprovada em 04 de dezembro de 2018, sendo 08 votos a favor e 02 abstenções, por meio da Resolução nº 04/2018, que instituiu a Base Nacional Comum Curricular na Etapa do Ensino Médio (BNCC-EM), como etapa final da 


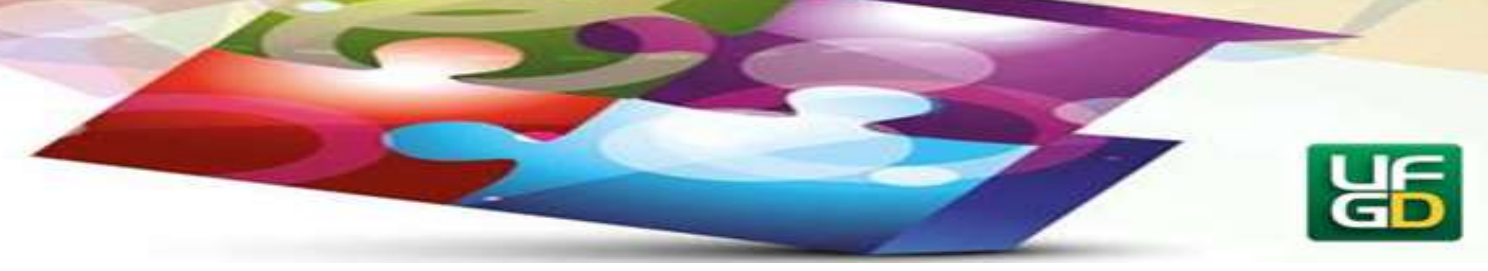

Educação Básica, nos termos do artigo 35da LDB, completando o conjunto constituído pela BNCC da Educação Infantil e do Ensino Fundamental, com base na Resolução CNE/CP n ${ }^{\circ}$ 2/2017 e fundamentada no Parecer CNE/CP n ${ }^{\circ}$ 15/2017.

Diante da mudança que se anuncia, a reforma curricular no país está em andamento e são muitos os desafios e as inquietações que perpassam os sistemas e redes de ensino no país, especificamente no âmbito da gestão e da prática pedagógica. Para dar conta de compreender e analisar essas mudanças, sobretudo no que se refere à área Ciências da Natureza e suas Tecnologias, as mediações analíticas realizadas na pesquisa perpassam pelos seguintes encaminhamentos: Primeiramente, abordaremos sobre o contexto histórico da reforma do Ensino Médio no qual também compreenderemos a BNCC e suas implicações para a política curricular. Em um segundo momento, expomos a compreensão sobre a BNCC do Ensino Médio. Por último, refletimos sobre as implicações da BNCC na área do conhecimento Ciências da Natureza e suas Tecnologias.

\section{Desenvolvimento}

Durante o governo de Michel Temer (2016) foi aprovada a Medida Provisória $\mathrm{n}^{\circ} 746 / 2016 q u e$ propunha alterações na Lei de Diretrizes e Bases da Educação (LDB). A lei no 13.415/2017 decorrente das propostas colocada na MP teve por objetivo modificar a organicidade do Ensino Médio, sua estruturação e organização, como também alterações do própriocurrículo do Ensino Médio por meio da aprovada BNCC.

A proposta da antiga MP ${ }^{\circ} 746$ era de que as 13 disciplinas do ensino médio passassem por transformações no qual seriam divididas por cinco itinerários, sendo eles: I- linguagens e suas tecnologias; II- matemática e suas tecnologias; III- ciências da natureza e suas tecnologias.; IV- ciências humanas e sociais aplicadas; V-formação técnica e profissional, e deixa apenas como disciplinas obrigatórias Português, Matemática e língua estrangeira. Os 60\% do tempo seria destinado às disciplinas obrigatórias e o restante, os $40 \%$ é voltado para o grau de interesse de cada aluno.

Com esta nova reforma instituída pela Lei $n^{\circ}$ 13.415/2017no Ensino Médio, uma questão polêmina gerada é que o governo passará a autorizar professores com notório saber, conforme estabelece o Art. 61, inciso IV: 


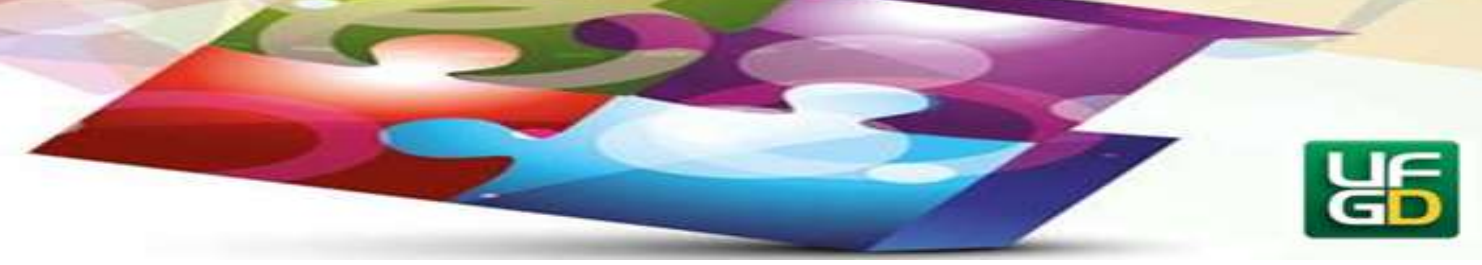

IV - profissionais com notório saber reconhecido pelos respectivos sistemas de ensino, para ministrar conteúdos de áreas afins à sua formação ou experiência profissional, atestados por titulação específica ou prática de ensino em unidades educacionais da rede pública ou privada ou das corporações privadas em que tenham atuado, exclusivamente para atender ao inciso V do caput do art. 36; (Incluído pela lei $\mathrm{n}^{\circ}$ 13.415, de 2017) (BRASIL, 1996, p. 06).

Essa mudança possibilita que profissionais sem licenciatura específica na área poderão dar aulas conforme os conteúdos de áreas afins da sua formação nas disciplinas técnicas e profissionalizantes, tambémão fica claro a exigência de um diploma acadêmico específico. Essa modificação está intrinsicamente ligada às mudanças no mundo do trabalho, pois de acordo com as análises de Moreira (2018, p. 205) as políticas educacionais que delineiam as atuais reformas na educação brasileirasão representações históricas, “expressam aspectos ideológicosproduzidas no contexto de mundialização da economia, na fase de vigência da acumulação financeirizada, flexível e do neoliberalismo.

Em outras palavras, o atual contexto traz uma concepção de escola e educação flexibilizada que visa atender aos imperativos do mercado e da visão empresarial a fim de propiciar "uma formação volátil, superficial e adestrada para suprir as necessidades do mercado de trabalho polivalente, multifuncional e flexível" (ANTUNES, 2017, p. 12). Para acompanhar essas mudanças configuradas no mundo do trabalho, cada vez mais se produz a ideia e a exigencia de que:

[...] o trabalho da maioria está cada vez mais desqualificado, intensificado e precarizado, como resultado do novo regime de acumulação. Do que se conclui que, do ponto de vista da gestão empresarial, a recomposição da unidade do trabalho não passa de ampliação de tarefas do trabalhador, sem que isto signifique uma nova qualidade na formação, de modo a possibilitar o domínio intelectual da técnica (KUENZER, 2005, p. 12).

Como consequência disso poderá se instalar um cenário de produção de "distúrbios" no conhecimento dos alunos, pois esses não alcançarão a compreensão das disciplinas que forem retiradas do currículo escolar. Deixando o indivíduo sem acesso ao conhecimento das áreas fundamentais. Saviani alerta que: 
[...] o modo como está organizada a sociedade atual é a referência para a organização do ensino fundamental. O nível de desenvolvimento atingido pela sociedade contemporânea coloca a exigência de um acervo mínimo de conhecimentos sistemáticos, sem o que não se pode ser cidadão, isto é, não se pode participar ativamente da vida da sociedade (SAVIANI, 2007, p. 160).

Com a retirada das disciplinasespecífica e nomeadas comosociologia, história, filosofia, geografia, ocorreu a substituição por área denominada de "Ciências Humanas e Sociais Aplicadas" foi possível identificar no próprio documento da BNCC que o foco se concentrou na análise e na avaliação das relações sociais, dos modelos econômicos, dos processos políticos e das diversas culturas (VICENTE, 2019, p. 187). A partir dessa mudança,os indivíduos poderão sofrer consequências de um retrocesso descomunal, pois a ciência específica desapareceu, ou seja, uma certa desvalorização do conteúdo disciplinar específico por área da Ciência se dissipará, dificultando a identificação do conteúdo ou conhecimento no âmbito da Geografia, História, a Filosofia e da Sociologia.

Todavia, o próprio documento da BNCC-EM ao destacar o Parecer CNE/CP nº 11/2019 salienta que:

A organização por áreas "não exclui necessariamente as disciplinas, com suas especificidades e saberes próprios historicamente construídos, mas, sim, implica o fortalecimento das relaçõesentre elas e a sua contextualização para apreensão e intervenção na realidade, requerendo trabalho conjugado e cooperativo dos seus professores no planejamento e na execução dos planos de ensino" (BRASIL, 2017, p. 32).

Resta saber como as instituições escolares efetivarão esse trabalho conjugado para a manutenção das disciplinas em sua estruturação curricular, uma vez que o documento norteador do currículo BNCC-EM apresenta o conteúdo como competências específicas de área relacionando um conjunto de habilidades que se nomeiam como "aprendizagens essencias a serem garantidas no âmbito da BNCC" (BRASIL, 2017, p. 33).

Sem a definição concreta do que é a História como Ciência nos currículos escolares, tendemos adescaracterizar a própria Ciência da História. No mesmo sentido, ocorre com as demais ciências. Com a retirada da Filosofia não conseguiremos mais ter cidadãos pensantes, pois é através dos filósofos que temos a compreensão do mundo no qual estamos inseridos atualmente. Sem a Sociologia, como teremos uma nova perspectiva de sociedade? Sem a 


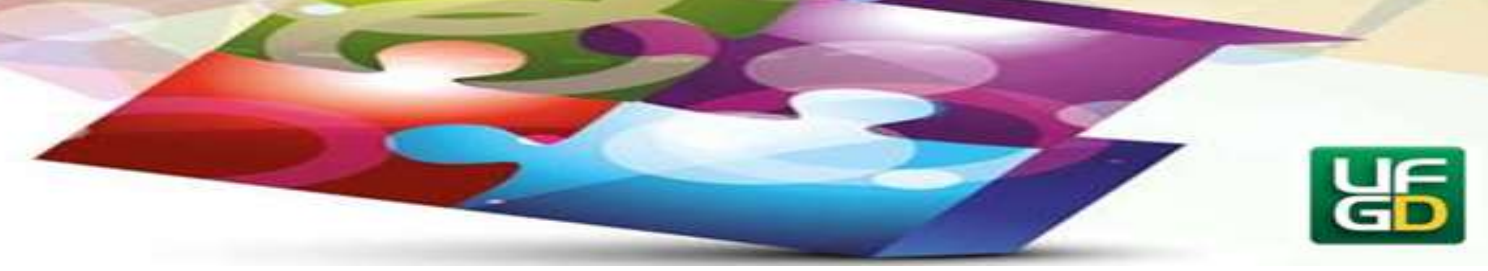

Geografia, não conseguiremos saber se houve alguma alteração no espaço geográfico causado pelos homens, pois se retirarem essas disciplinas ou dissiparem os seus conteúdos do currículo escolar não teremos a formação de sujeitos críticos e pensantes da sua própria realidade histórica.

A Educação ao ter por finalidade a transmissão dos diferentes conhecimentos. É um campo amplo no qual não se refere apenas ao espaço escolar. Há saberes que acontecem em cada espaço onde a educação é realizada, seja na família, igreja, escola etc. O espaço da escola é privilegiado dentro da sociedade para realização da prática educativa. A escola é o campo de aprendizagem dos conhecimentos científicos e culturais essenciais para a vida dentro da sociedade no qual o indivíduo está inserido, portanto, é por meio do ensino da escola que os alunos se desenvolvem como cidadãos críticos. Todo cidadão brasileiro tem o direito a Educação gratuita e de qualidade, conforme estabelece a Constituição Federal de 1988, no Art 205:

A educação, direito de todos e dever do Estado e da família, será promovida e incentivada com a colaboração da sociedade, visando ao pleno desenvolvimento da pessoa, seu preparo para o exercício da cidadania e sua qualificação para o trabalho.

Referente ao currículo escolar, Saviani (2003) aborda que é fundamental separar o que é essencial e secundário, o fundamental e o acessório no contexto educativo. $\mathrm{O}$ autor tem por base a concebida Pedagogia Histórico-Crítica, no qual "[...] não se confunde com o tradicional e também não se opõe, necessiariamente, ao moderno e muito menos ao atual. O clássico é aquilo que se firmou como fundamental, como essencial'" (SAVIANI, 2003, p. 13). Isso significa que a escola tem por objetivo levar ao aluno o saber sistematizado. Nesse sentido, a escola é o local onde ocorre a sistematização e produção do conhecimento. Saviani (2003) traz o conceito de "clássico" à tona, no qual enfatiza que é essencial o conhecimento, pois ele nos revela o que deve ser prioridade no ensino sistematizado.

Ao considerar e defender, mediante Saviani (2003), umaeducação clássica escolar, cabe conceituar que essa educação se refere à compreensão do mundo e sua transformação, é a transmissão-assimilação do conhecimento no qual a criança passa do estado de não conhecimento para a assimilação, apropriação de novos conhecimentos. 


\section{HORIZONTES - REVISTA DE EDUCACATO}

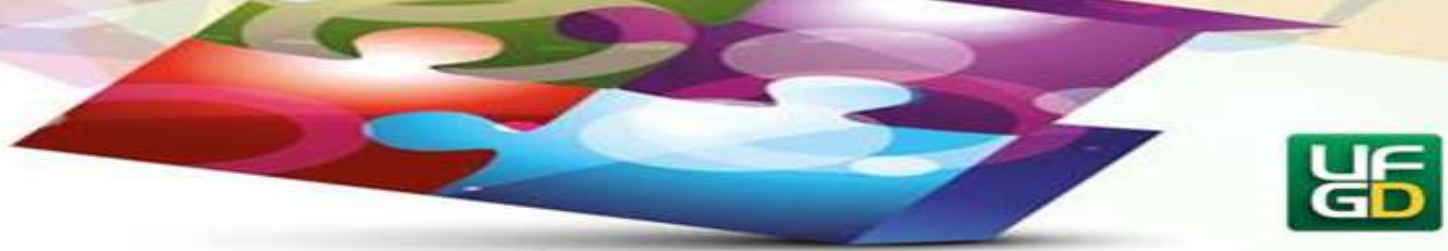

Diante do exposto, com o atual documento basilador do currículo escolar, denominado de BNCC e que norteia as áreas do ensino na educação básica salienta-se alguns aspectos gerais do documento no qual define "[...] o conjunto de aprendizagens a serem desenvolvidas no decorrer da Educação Básica, a qual busca garantir os direitos de aprendizagem e desenvolvimento em consonância com o PNE (VICENTE, 2019, p. 186).

Conforme o mesmo autor ressalta-se que este documento tem como objetivo o alinhamento das políticas e ações na esfera federal, estadual e municipal, no tocante à formação de professores, à avaliação, elaboração de conteúdos e estrutura física adequada para o desenvolvimento da educação (BRASIL, 2018).

No que se refere à BNCC do Ensino Médio enfatize-se que seguindo a mesma lógica da BNCC das etapas Educação Infantil e Ensino Fundamental, tal documento busca o desenvolvimento de competências gerais que orientam as aprendizagens essenciais a serem asseguradas no ensino médio, no tocante aos itinerários formativos a serem oferecidos pelos diferentes sistemas, redes e escolas (BRASIL, 2018). Para além da necessidade de universalizar o atendimento, o desafio do Ensino Médio, de acordo com Vicente (2019, p.186) no contexto atual "é de garantir a permanência e as aprendizagens dos estudantes".

A BNCC do Ensino Médio está organizada em quatro áreas do conhecimento, sendo: Linguagens e suas Tecnologias, Matemática e suas Tecnologias, Ciências da Natureza e suas Tecnologias, Ciências Humanas e Sociais Aplicadas, segundo a LDB (Art. 35-A, BRASIL, 1996a). A divisão da BNCC em itinerários formativos tem como finalidade a integração de dois ou mais componentes do currículo para melhor compreensão do grau de complexidade dos conteúdos que são abordados em cada área (BNCC, 2018). De acordo com o Parecer CNE/CP

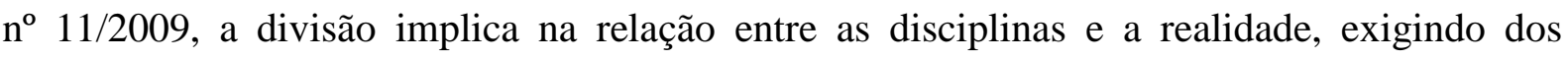
professores a realização de trabalho em conjunto tanto no planejamento como na execução das atividades.

Vale ressaltar, de acordo com Vicente (2019) na BNCC são definidas 187competências direcionadas para cada área do conhecimento, que orientam os itinerários formativos. No quadro abaixo elaborado elencam-se as competências específicas para as áreas de conhecimento da BNCC do ensino médio:

Quadro 01 - Competências específicas das áreas do conhecimento: BNCC do Ensino Médio. 


\section{HORIZONTES - REVISTA DE EDUCACATO}

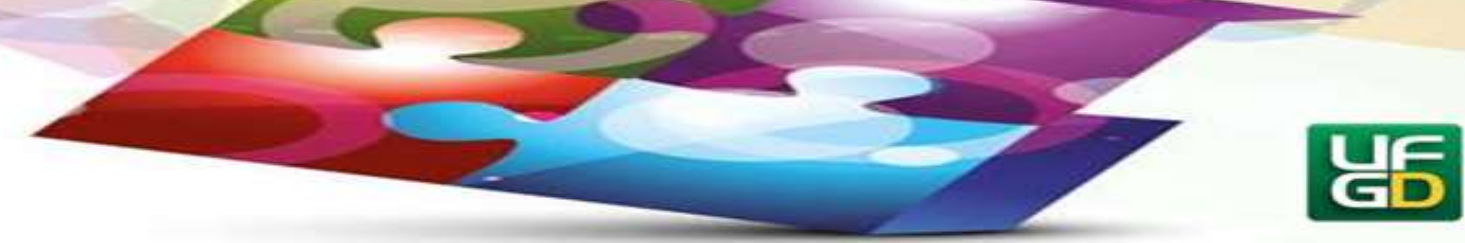

\begin{tabular}{|l|l|}
\hline \multicolumn{1}{|c|}{$\begin{array}{c}\text { Área de } \\
\text { Conhecimento }\end{array}$} & \multicolumn{1}{c|}{ Competências Específicas (foco da área) } \\
\hline $\begin{array}{l}\text { Linguagens e suas } \\
\text { Tecnologias }\end{array}$ & $\begin{array}{l}\text { Ampliação da autonomia, do protagonismo e da autoria nas práticas de } \\
\text { diferentes linguagens, na identificação e na crítica aos diferentes usos das } \\
\text { linguagens, explicitando seu poder no estabelecimento de relações, na } \\
\text { apreciação e na participação em diversas manifestações artísticas e } \\
\text { culturais e no uso criativo das diversas mídias. }\end{array}$ \\
\hline $\begin{array}{l}\text { Matemática e suas } \\
\text { Tecnologias }\end{array}$ & $\begin{array}{l}\text { Os estudantes devem utilizar conceitos, procedimentos e estratégias não } \\
\text { apenas para resolver problemas, mas também para formulá-los, descrever } \\
\text { dados, selecionar modelos matemáticos e desenvolver pensamento } \\
\text { computacional, por meio da utilização de diferentes recursos da área. }\end{array}$ \\
\hline $\begin{array}{l}\text { Ciências da Natureza e } \\
\text { suas Tecnologias }\end{array}$ & $\begin{array}{l}\text { Propõe que os estudantes possam construir e utilizar conhecimentos da } \\
\text { área, para argumentar, propor soluções e enfrentar desafios locais e/ou } \\
\text { globais, relativos às condições de vida e ao ambiente. }\end{array}$ \\
\hline $\begin{array}{l}\text { Ciências Humanas e } \\
\text { Sociais Aplicadas }\end{array}$ & $\begin{array}{l}\text { Concentra-se na análise e na avaliação das relações sociais, dos modelos } \\
\text { econômicos, dos processos políticos e das diversas culturas. }\end{array}$ \\
\hline
\end{tabular}

Fonte: Elaborado por Vicente (2018), baseado na Base Nacional Comum Curricular preliminar do Ensino Médio (BRASIL, 2017c).

Com relação a área denominada de Ciências da Natureza e suas Teconologias, a Resolução CNE/CEB n 3/2018, no art. 12 apresenta que devem abordar assuntos como:

[...] aprofundamento de conhecimentos estruturantes para aplicação de diferentes conceitos em contextos sociais e de trabalho, organizando arranjos curriculares que permitam estudos em astronomia, metrologia, física geral, clássica, molecular, quântica e mecânica, instrumentação, ótica, acústica, química dos produtos naturais, análise de fenômenos físicos e químicos, meteorologia e climatologia, microbiologia, imunologia e parasitologia, ecologia, nutrição, zoologia, dentre outros, considerando o contexto local e as possibilidades de oferta pelos sistemas de ensino (BRASIL, 2018, p. 477).

Nota-se que a BNCC-EM impõe a ideia de que o conhecimento deve ser utilizado para fazer algo, ou seja, o conhecimento deve ser utilitário, sendo associado à obtenção de um produto final, isto é, envolve a ação do estudante para a resolução de problemas, sejam estes solucionados em campo ou através de pesquisas em laboratórios. O exposto na BNCC nosleva a pensar que a concepção de ciência ainda está baseada na obtenção de resultados, conforme preconiza o autor:

De meados do século XIX até hoje a ciência adquiriu total hegemonia no pensamento ocidental e passou a ser socialmente reconhecida pelas virtualidades instrumentais da sua racionalidade, ou seja, pelo desenvolvimento tecnológico que tornou possível. A partir desse momento, o conhecimento científico pode dispensar a investigação das suas causas como 
meio de justificação. Socialmente passou a justificar-se, não pelas causas, mas pelas suas conseqüências (SANTOS, 1989, p. 28).

A solução de problemas mediante essa concepção de Ciência pode acarretar consequências graves em vários aspectos, que afetam diretamente a vida em sociedade, já que pode ocasionar problemas ao meio ambiente como o desmatamento, a caça e a coleta de animais realizadas de maneira incorreta para pesquisas de laboratório. Um exemplo disso está no princípio dos 3 Rs difundida no âmbito dos experimentos científicos:

O princípio dos 3 Rs (Reduction, Refinement, Replacement), propõe a redução do número de animais utilizados no experimento - reduction; o refinamento das técnicas visando evitar a dor e o sofrimento desnecessários refinement; e a substituição dos testes com animais por métodos alternativos - replacement. O refinamento de tecnologias e de modelos experimentais também pode ser trabalhado quanto a redução da variabilidade da resposta, o que leva a diminuição do número de animais utilizados nos grupos experimentais (CRISSIUMA; ALMEIDA, 2006, p. 04).

Outro fator de importante relevância é que para solucionar problemas científicos, muitas vezes se faz necessário o uso de tecnologias que podem também acarretar em danos para o ambiente. Muitas indústrias, por exemplo, utilizam equipamentos que geram uma poluição exacerbada. Na legislação ambiental que trata do direito ambiental apresenta-se alguns princípios. Entre eles está o princípio do Poluidor-Pagador, que atribui as responsabilidades de eventuais danos ambientais decorrentes da poluição totatalmente para o responsável em causar o dano, ou seja, é:

[...] o princípio que usa para afetar os custos das medidas de prevenção e controle da poluição, para estimular a utilização racional dos recursos ambientais escassos e para evitar distorções ao comércio e ao investimento internacionais, é o designado princípio do poluidor-pagador. Este princípio significa que o poluidor deve suportar os custos do desenvolvimento das medidas acima mencionadas decididas pelas autoridades públicas para assegurar que o ambiente esteja num estado aceitável [...] (ARAGÃO, 1997, p. 60).

As punições atribuídas ao responsável pela poluição, de acordo com esse princípio, vão desde o pagamento de multa, até em alguns casos, o reestabelecimento in natura da área afetada, quando possível. É relevante ressaltar que a Constituição de 1988 já estabelece a necessidade 


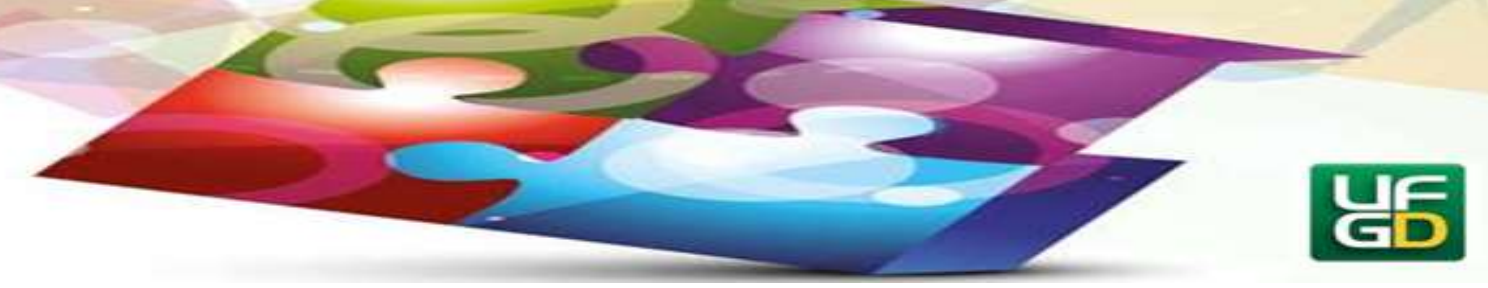

de haver um equilíbrio ambiental em seu Art. 225: "Todos têm direito ao meio ambiente ecologicamente equilibrado, bem de uso comum do povo e essencial à sadia qualidade de vida, impondo-se ao poder público e à coletividade o dever de defendê-lo e preservá-lo para as presentes e futuras gerações" (BRASIL, 1988).

A BNCC-EM enquanto documento norteador do currículo escolar traz na parte atribuída às "Ciências da Natureza e suas Tecnologias", uma ideia de utilização do conhecimento que é aprendido no ambiente escolar para a produção e solução de questionamentos, que podem levar à consequências irreparáveis. Está inserido nessa perspectiva a ideia de qualificação profissional do aluno. Cada vez mais se exige uma diferenciação ao modo de se ensinar e o que ensinar, o que segundo Antunes (2017, p. 9) não necessariamente "significa que conhecimentos básicos e científicos sejam imediatamente úteis ao trabalho". Daí a importância dada na BNCCEM às qualificações comportamentais, pautada na competência e habilidade do aluno e da escola. Sobre essa questão Kuenzer analisa que:

[...] o mercado de trabalho passa a reger-se pela lógica dos arranjos flexíveis de competências diferenciadas. [...] Se há combinação entre trabalhos desiguais e diferenciados ao longo das cadeias produtivas, há também demandas diferenciadas, e desiguais, de qualificação dos trabalhadores, que podem ser rapidamente atendidas pelas estratégias de aprendizagem flexível, o que permite que as contratações sejam definidas a partir de um perfil de trabalhador com aportes de educação geral e capacidade para aprender novos processos, e não a partir da qualificação (KUENZER, 2016, p. 04).

O currículo deve ter como base o cientificismo e propor que o "processo de ensino deve transmitir aos alunos a lógica do conhecimento de referência. [...] é do saber especializado e acumulado pela humanidade que devem ser extraídos os conceitos e os princípios a serem ensinados aos alunos" (LOPES, 2002, p. 151-152). Cabe salientar que a disciplina de biologia no Ensino Médio tem grande influência da sociologia e da filosofia, já que a sociedade está em constante transformação e a natureza se modifica junto com a sociedade. Nesse entendimento é possível considerar de que a Ciência está sujeita à mudanças e determinações provenientes das transformações sociais e das necessidades materiais dos homens. Todavia, sofre sua interferência, mas também interfere (ANDERY, 1988; ARAÚJO, 2002).

A biologia se relaciona com o desenvolvimento humano e social, então não se resume apenas à ideia de pesquisas que se realizam em laboratório ou pesquisas de campo, mais do que 


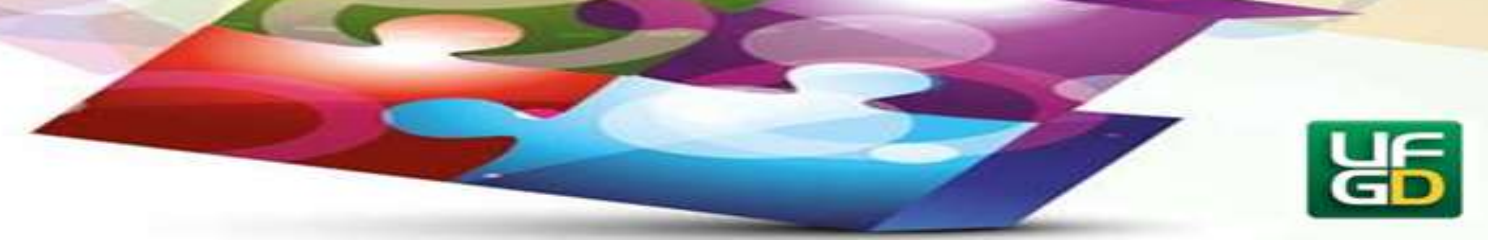

isso, ela é capaz de interferir no dia-a-dia. As mudanças que ocorrem a todo momentoexigem um acompanhamento por parte da ciência, pois assim como Kneller (1980) defendemos que:

A Ciência é intrinsecamente histórica. Não somente o conhecimento científico, mas também as técnicas pelas quais ele é produzido, as tradições de pesquisa que o produzem e as instituições que as apoiam, tudo isso muda em resposta a desenvolvimentos nelas e no mundo social e cultural a que pertencem. Se quisermos entender o que a Ciência realmente é, devemos considerá-la em primeiro lugar e acima de tudo uma sucessão de movimentos dentro do movimento mais amplo da própria civilização (KNELLER, 1980, p. 13).

Nas escolas, o currículo de ciências no Ensino Fundamental e de biologia no Ensino Médio infelizmente traz a ideia de que só fazemos ciência quando produzimos algo em laboratório ou solucionamos algum problema, com base em alguma teoria. Essa visão da ciência tem que ser superada, pois o aluno não tem que ser forçado a fazer ciência, ele deve enxergar que a ciência se encontra no cotidiano e que todos são capazes de fazer ciência, portanto, a motivação deve vir em primeiro lugar.

O ensino médio é a etapa final da educação básica e de acordo com a BNCC necessita ser universalizado para melhorar quesitos como a permanência do aluno na escola, além de garantir que as necessidades dos estudantes sejam atendidas para que os mesmos sintam prazer em estar no ambiente escolar e não considere a escola apenas como uma obrigação diária.

As Diretrizes Curriculares Nacionais Gerais da Educação Básica (BRASIL, 2013, p. 04), lançadas pelo MEC, afirmam que a base nacional comum será "responsável por orientar a organização, articulação, o desenvolvimento e a avaliação das propostas pedagógicas de todas as redes de ensino brasileiras". Mediante o documento a área de "Ciências da Natureza e suas Tecnologias" no ensino médio engloba as disciplinas de física, química e biologia e, tem a função de garantir que o aluno relembre e interiorize todos os conceitos aprendidos durante o ensino fundamental e seja capaz de relacioná-los com a cultura, a história, o ambiente e a sociedade.

Na BNCC, a física se divide em 6 partes: Movimentos de objetos e sistemas; Energias e suas transformações; Processos de Comunicação e Informação; Eletromagnetismo - materiais e equipamentos; Materiais e radiações; Terra e Universo - formação e evolução (MARCONDES, 2018, p. 278). Segundo a autora, a química também se divide em 6 partes: 


\section{HORIZONTES - REVISTA DE EDUCACATO}

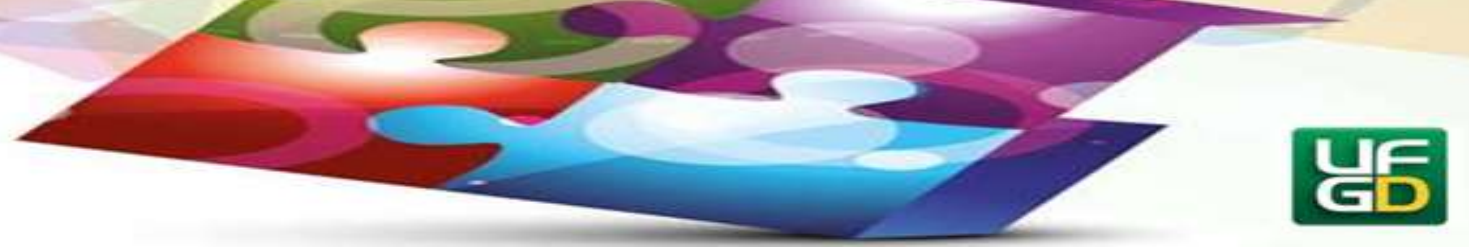

Materiais, propriedades e usos: estudando materiais no dia a dia; Transformações dos Materiais na Natureza e no Sistema Produtivo: Como Reconhecer Reações Químicas, Representá-las e Interpretá-las; Modelos atômicos e moleculares e suas relações com evidências empíricas e propriedades dos materiais; Energia nas Transformações Químicas: Produzindo, Armazenando e Transportando Energia pelo Planeta; A química de sistemas naturais: qualidade de vida e meio ambiente. Obtenção deMateriais e seus Impactos Ambientais.

A autora aponta ainda, que a biologia é composta por 6 unidades, sendo elas: vida como fenômeno e seu estudo; Biodiversidade: organização, caracterização e distribuição dos organismos vivos; Organismo: sistema complexo e autorregulável; Hereditariedade: padrões e processos de armazenamento, transmissão e expressão de informação; Evolução: padrões e processos de diversificação da vida; Ecossistemas: interações organismo-meio.

De acordo com a BNCC (BRASIL, 2018), a Ciência e a Tecnologia tendem a ser encaradas não somente como ferramentas capazes de solucionar problemas, tanto os dos indivíduos como os da sociedade, mas também como uma abertura para novas visões de mundo. Nesse sentido, na BNCC-EM os conhecimentos conceituais são aqueles que englobam leis, teorias e modelos, por isso conteúdos presentes na BNCC do ensino fundamental são aprofundados, como exemplo, pode-se citar: Matéria e Energia, Vida e Evolução e Terra e Universo:

Os conhecimentos conceituais associados a essas temáticas constituem uma base que permite aos estudantes investigar, analisar e discutir situaçõesproblema que emerjam de diferentes contextos socioculturais, além de compreender e interpretar leis, teorias e modelos, aplicando-os na resolução de problemas individuais, sociais e ambientais. Dessa forma, os estudantes podem reelaborar seus próprios saberes relativos a essas temáticas, bem como reconhecer as potencialidades e limitações das Ciências da Natureza e suas Tecnologias (BRASIL, 2018, p. 548).

Na subdivisão Matéria e Energia, são discutidos temas como condutibilidade elétrica, os gases, a radioatividade, já na subdivisão Vida, Terra e Cosmos, que une Vida, Evolução, Terra e Universo, trabalha assuntos como a evolução da vida, principalmente humana, as interações que ocorrem em nosso planeta (reações nucleares, processos estelares), entre outros.

Para abordar a questão histórica, a BNCC enfatiza que deve se associar as descobertas da ciência com a política, a economia, a sociedade de cada local, levando em consideração, principalmente a época em que os fatos ocorrem. 


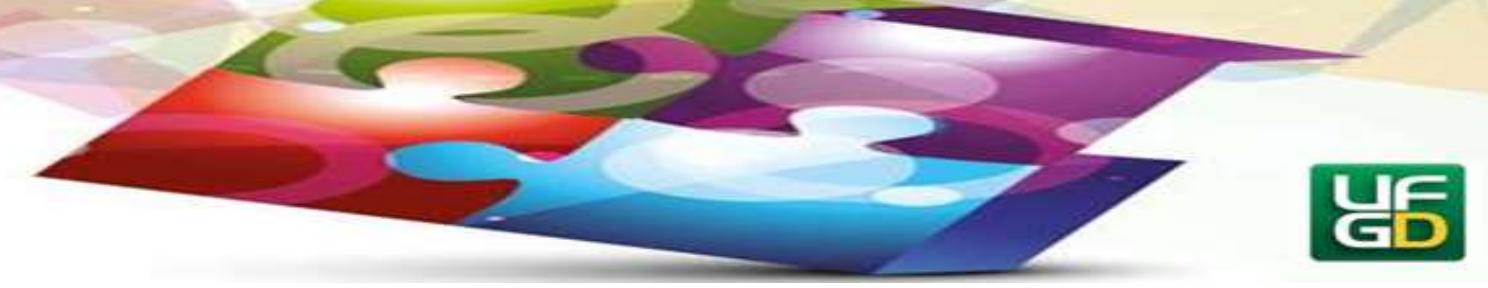

As competências e habilidades da BNCC-EM abrangem a melhoria da qualidade de vida, segurança, sustentabilidade, diversidade étnica e cultural, para que o aluno possa compreender os processos científicos. O estudante também tem que ser capaz de relacionar a ciência e a tecnologia, considerando a informática, o geoprocessamento, etc, além de ter capacidade para discutir diferentes teorias científicas.

Os processos e práticas da investigação, de acordo com a BNCC-EM, devem ser enfatizados. O aluno deve ser capaz de propor e solucionar problemas, criar hipóteses, descartálas quando necessário, devendo também haver a discussão das diferentes teorias para que haja o desenvolvimento da argumentação:

\begin{abstract}
A abordagem investigativa deve promover o protagonismo dos estudantes na aprendizagem e na aplicação de processos, práticas e procedimentos, a partir dos quais o conhecimento científico e tecnológico é produzido. Nessa etapa da escolarização, ela deve ser desencadeada a partir de desafios e problemas abertos e contextualizados, para estimular a curiosidade e a criatividade na elaboração de procedimentos e na busca de soluções de natureza teórica e/ou experimental (BRASIL, 2018, p. 551).
\end{abstract}

Diante dessas definições, a BNCC-EM aponta que os alunos devem ser capazes de entender a linguagem científica. Pode-se citar a nomenclatura existente nas disciplinas de botânica e zoologia, em que as espécies vegetais (Botânica) e animais (Zoologia) são reconhecidas por nomescientíficos escritos em latim.

Ao analisar as competências específicas presentes na área de "Ciências da Natureza e suas Tecnologias" identificamos categorias políticas por meio de uma categorização. A partir de Bardin (1977), a categorização é:

[...] uma operação de classificação de elementos constitutivos de um conjunto, por diferenciação e, seguidamente, por reagrupamento segundo o gênero (analogia), com critérios previamente definidos. As categorias, são rubricas ou classes, as quais reúnem um grupo de elementos (unidades de registro, no caso da análise de conteúdo) sob título genérico, agrupamento esse efetuado em razão dos caracteres comuns destes elementos (BARDIN, 1977, p. 117, grifos da autora).

Ao identificar esses elementos constitutivos nas competências específicas da área Ciências da Natureza e suas Tecnologias estamos a conceber as categorias elencadas comoconceitos básicos que expressam elementos essenciais do real, bem como suas relações e 


\section{HORIZONTES - REVISTA DE EDUCACATO}

e-ISSN: $2318-1540$

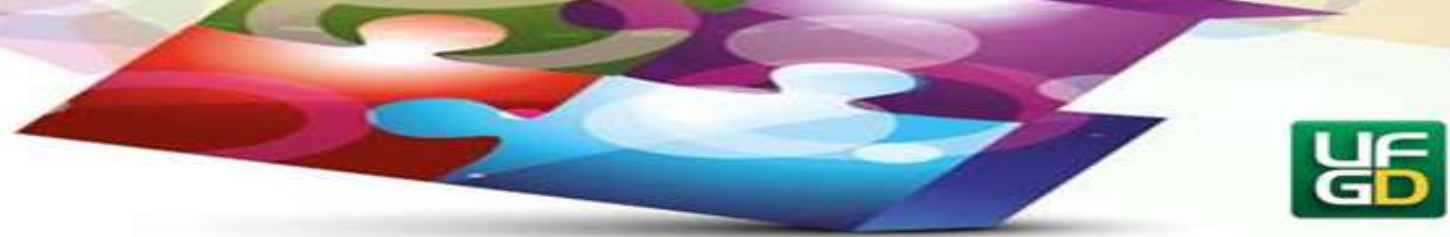

conexões. Conforme Cury (1987) conceitua as categorias são instrumentos metodológicos de análise que auxiliam a compreensão dos aspectos que constituem o todo da realidade social e, em especial, os elementos da educação. Portanto, são expressões conceituais, não são neutras e se revelam comprometidos com uma determinada visão de mundo.

Assim, foi possível identificar a seguinte categorização:

Quadro 02 - Categorização políticas presentes nas competências específicas da área de Ciências da Natureza e suas Tecnologias na BNCC-EM.

\begin{tabular}{|c|c|c|}
\hline & $\begin{array}{c}\text { Competências Específicas de Ciências da Natureza e suas } \\
\text { Tecnologias para o Ensino Médio }\end{array}$ & Categorias \\
\hline 1. & $\begin{array}{l}\text { Analisar fenômenos naturais e processos tecnológicos, com base nas } \\
\text { interações e relações entre matéria e energia, para propor ações } \\
\text { individuais e coletivas que aperfeiçoem processos produtivos, } \\
\text { minimizem impactos socioambientais e melhorem as condições de } \\
\text { vida em âmbito local, regional e global (BNCC-EM, 2017, p. } 540 . \\
\text { Grifos Nossos) }\end{array}$ & $\begin{array}{l}\text { Propor ações-Agir } \\
\text { Produzir } \\
\text { Melhorar } \\
\text { Resultados }\end{array}$ \\
\hline 2. & $\begin{array}{l}\text { Analisar e utilizar interpretações sobre a dinâmica da Vida, da Terra e } \\
\text { do Cosmos para elaborar argumentos, realizar previsões sobre o } \\
\text { funcionamento e a evolução dos seres vivos e do Universo, e } \\
\text { fundamentar e defender decisões éticas e responsáveis (BNCC-EM, } \\
2017 \text {, p. 542. Grifos Nossos) }\end{array}$ & $\begin{array}{l}\text { Utilizar } \\
\text { Realizar } \\
\text { Defender } \\
\text { Decidir }\end{array}$ \\
\hline 3. & $\begin{array}{l}\text { Investigar situações-problema e avaliar aplicações do conhecimento } \\
\text { científico e tecnológico e suas implicações no mundo, utilizando } \\
\text { procedimentos e linguagens próprios das Ciências da Natureza, para } \\
\text { propor soluções que considerem demandas locais, regionais e/ou } \\
\text { globais, e comunicar suas descobertas e conclusões a públicos } \\
\text { variados, em diversos contextos e por meio de diferentes mídias e } \\
\text { tecnologias digitais de informação e comunicação (TDIC) (BNCC-EM, } \\
2017 \text {, p. 544. Grifos Nossos). }\end{array}$ & $\begin{array}{l}\text { Aplicar } \\
\text { Utilizar } \\
\text { Solucionar } \\
\text { Comunicar em redes }\end{array}$ \\
\hline
\end{tabular}

Fonte:Elaborado pelas autoras (2019). Dados retirados da BNCC (BRASIL, 2017, p. 540-544).

Coincidentemente quase todas as categorias políticas que identificamos representam verbos de ação pelo critério semântico e aparecem nos enunciados das competências específicas para a área Ciências da Natureza e suas Tecnologias na BNCC-EM, como indicando um "fazer" por parte do sujeito, um "processo de atividade". Nessa perspectiva o conhecimento será divulgado como novos produtos.

A primeira competência engloba os fenômenos naturais e os estudos referentes à Matéria $\mathrm{e}$ Energia cujo foco é a percepção por parte dos alunos das potencialidades, riscos e limites de diferentes materiais, relacionados às distintas tecnologias. $\mathrm{O}$ aluno deve ser capaz de tomar 
decisões corretas diante das situações diárias. De acordo com a BNCC nessa competência cabem assuntos como:

Estrutura da matéria; transformações químicas; leis ponderais; cálculo estequiométrico; princípios da conservação da energia e da quantidade de movimento; ciclo da água; leis da termodinâmica; cinética e equilíbrio químicos; fusão e fissão nucleares; espectro eletromagnético; efeitos biológicos das radiações ionizantes; mutação; poluição; ciclos biogeoquímicos; desmatamento; camada de ozônio e efeito estufa; desenvolvimento e aprimoramento de tecnologias de obtenção de energia elétrica; processos produtivos como o da obtenção do etanol, da cal virgem, da soda cáustica, do hipoclorito de sódio, do ferro-gusa, do alumínio, do cobre, entre outros (BRASIL, 2018, p. 554).

Para essa competência a BNCC-EM recomenda que é vantajoso utilizar as tecnologias digitais no âmbito de cada habilidade. Nesta competência, o aluno precisa compreender a importância das transformações e da evolução, que ocorrem das moléculas às estrelas em tempos diferentes. Os estudantes serão capazes de criarem reflexões sobre a humanidade e o planeta terra. Permite-se entender também a vida e seus níveis de organização, para que os alunos entendam a importância de preservar os recursos da natureza, além de saberem as limitações do conhecimento científico.Essa competência permite estudos relacionados com:

Origem da Vida; evolução biológica; registro fóssil; exobiologia; biodiversidade; origem e extinção de espécies; políticas ambientais; biomoléculas; organização celular; órgãos e sistemas; organismos; populações; ecossistemas; teias alimentares; respiração celular; fotossíntese; neurociência; reprodução e hereditariedade; genética mendeliana; processos epidemiológicos; espectro eletromagnético; modelos atômicos, subatômicos e cosmológicos; astronomia; evolução estelar; gravitação; mecânica newtoniana; previsão do tempo; história e filosofia da ciência; entre outros (BRASIL, 2018, p. 556).

Quanto a segunda competência o foco está na utilização dos conhecimentos sobre a vida, terra e o cosmos. A aprendizagem na visão das competências deve gerar comportamentos de preservação do meio ambiente, de forma ética e responsável, com previsões para Utilizar, Realizar, Defender e Decidir. 


\section{HORIZONTES - REVISTA DE EDUCACATO}

Portanto, a mesma lógica está presente na terceira competência no qual o foco está em Aplicar, Utilizar, Solucionar e Comunicar resultados e novos conhecimentos em redes, por diferentes mídias e tecnologias de informação e comunicação digital (TDIC).

Pode-se destacar que naatualidade temos muitas informações ao nosso redor que são veiculadas pelos diversos meios de comunicação e, por isso, a BNCC-EM destaca comonecessário que os estudantes tenham senso crítico e discernimento para saberem descartar o que falso. A mesma cautela deve se ter com o conhecimento científico.É relevante que os alunos compreendam o impacto da tecnologia nos dias de hoje, principalmente para a convivência em sociedade, já que existem diferenças culturais, por exemplo, e é fundamental sempre utilizar a ética, que é indispensável na ciência.

Por meio dessa e das outras competências, é esperado que os alunos tenham curiosidade para novas descobertas, que sejam capazes de desenvolver a criticidade para solucionar problemas e desenvolver hipóteses. Espera-se também que a linguagem científica possa ser vista com menos complexidade.Essa competência permite discutir temas como:

A aplicação da tecnologia do DNA recombinante; identificação por DNA; emprego de células-tronco; neurotecnologias; produção de tecnologias de defesa; estrutura e propriedades de compostos orgânicos; isolantes e condutores térmicos, elétricos e acústicos; eficiência de diferentes tipos de motores; matriz energética; agroquímicos; controle biológico de pragas; conservantes alimentícios; mineração; herança biológica; desenvolvimento sustentável; vacinação; darwinismo social, eugenia e racismo; mecânica newtoniana; equipamentos de segurança etc (BRASIL, 2018, p. 559).

Percebe-se que o modo como está estruturada a BNCC do ensino médio na área de “Ciências da Natureza e suas Tecnologias" não estabelece uma divisão seriada dos conteúdos, justamente por estar dividida em habilidades e competências, no qual de acordo com a BNCC os assuntos podem ser abordados desde o $1^{\circ}$ até o $3^{\circ}$ ano do ensino médio.Outra questão que nos leva a considerar é que os sistemas e redes de ensino deverão, a partir da BNCC, elaborar uma interpretação a partir do estabelecido na BNCC e compor assim, um quadro de conteúdos nos seus currículos. Salienta-se que essa divisão em habilidades e competências presentes na BNCC (2018) foi estabelecida anteriormente pelos Parâmetros Curriculares Nacionais (PCN), como se pode perceber pelo descrito nas Diretrizes Curriculares da Educação Básica-Biologia do estado do Paraná (2008): 


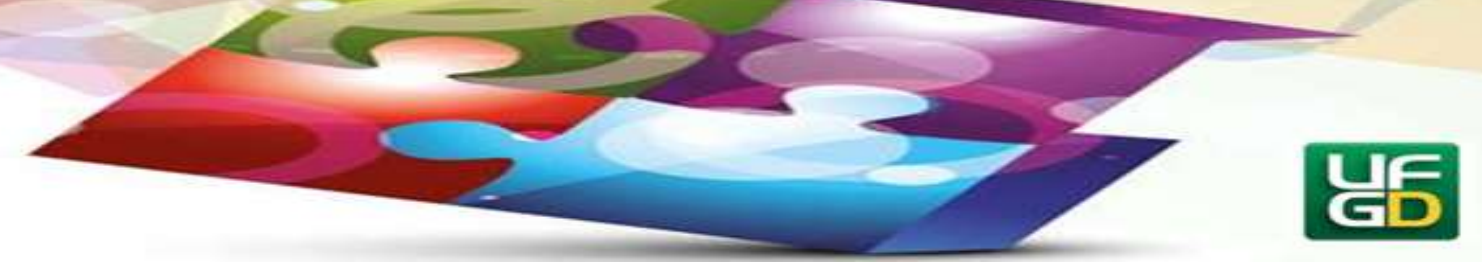

Os Parâmetros Curriculares Nacionais (PCN) enfatizaram o desenvolvimento de competências e habilidades em prejuízo de uma abordagem mais aprofundada dos conteúdos, direcionando o ensino para temas e desenvolvimento de projetos considerados necessários para ávida do aluno. Os conceitos básicos de Biologia foram apresentados de forma reducionista, sem uma abordagem histórica, e controlados pela competência individual (PARANÁ, 2008, p. 49).

Esse modelo se permanecer dessa forma poderá deixarincerto o tipo de abordagem dos temas e com isso o aluno pode acabar tendo um aprendizado não tão satisfatório.A BNCC-EM (2018) na parte das Ciências da Natureza e suas Tecnologias estabelece conteúdos conceituais, mas não mostra um caminho que o professor possa seguir, no sentido de como ensinar. Nesse sentido, o trabalho do docente poderá expressar dificuldades, pois ficará a seu critério, na elaboração do plano de trabalho e a critério da escola ao estabelecer o Projeto Político Pedagógico (PPP), decidir quais habilidades e competências serão ensinadas em cada ano. Salienta-se que não há uma prerrogativa nítida quanto a divisão dos conhecimentos em habilidades e competências, a não ser a presença da lógica produtiva que foi apresentada nesse texto.

\section{Considerações Finais}

Ao encerrar as discussões aqui mediadasconcluiu-se que as recentes alterações ocorridas no governo de Michel Temer (2016) por meio das alterações na Lei de Diretrizes e Bases da Educação $n^{\circ}$ 9394/96 mediante a Lei no 13.415 em 16 de fevereiro de 2017, que foi aprovada após a medida provisória $\mathrm{n}^{\circ} 746 / 2016$, desencadearam modificações no currículo do ensino médio, que entraram em vigor após a aprovação da Base Nacional Comum Curricular (BNCC) para o Ensino Médio (BRASIL, 2018).

Dentre as modificações ocorridas notou-se que houve um processo anacrônico no Ensino Médio, com a retirada da obrigatoriedade das disciplinas de Sociologia e Filosofia, tornando as mesmas opcionais. O que gera questionamentos e incertezas no âmbito educacional com relação à formação do pensamento crítico, sem as disciplinas de Sociologia e Filosofia enquanto matérias obrigatórias nas escolas que promovem a capacidade de construir 


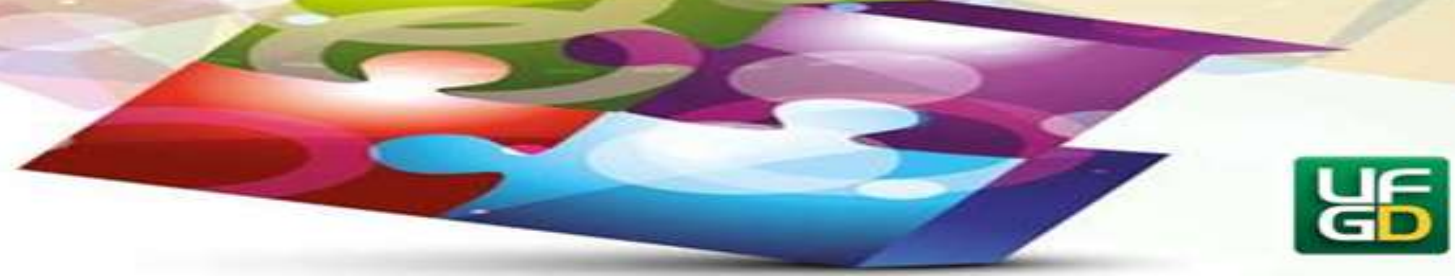

argumentos relevantes para a convivência em sociedade e para a compreensão da natureza e suas tecnologias, objetivo também da própria área do ensino de Ciências.

Ao compreender sobre a estrutura da BNCC, no qual cabe o questionamento se a divisão em itinerários formativos, com ênfase nas habilidades e competências é a maneira mais adequada para o currículo do Ensino Médio, observou-se que essa divisão não deixa claro, quais são os conteúdos estudados em cada série.

No que se refere especificamente a BNCC do Ensino Médio e a área de "Ciências da Natureza e suas Tecnologias" percebeu-se que o documento tem a concepção da ciência pautado em competências e habilidades para o ato de produzir. Nessa lógica, o aluno tem que ser capaz de utilizar a tecnologia e outros meios para solucionar problemas, levantar questionamentos, informar e divulgar os conhecimentos gerados por meio de produtos, ou seja, é a lógica da ciência pautada na ação. Na BNCC, a área de "Ciências da Natureza e suas Tecnologias" não se divide em conteúdos, assim como todo o documento, o que leva-nos a entender a necessidade de adotar as diretrizes curriculares para elaborar a divisão dos conceitos presentes na BNCC de acordo com o ano/período do aluno e para a elaboração do PPP de cada escola, rede e sistemas de ensino no país. Os desafios que se colocam são intensos e carecemos de uma preservação dos avanços já conquistados pelas instituições e sistemas de ensino no que se refere às propostas curriculares, gestão democrática, autonomia do professor e tendências pedagógicas progressistas.

\section{Referências}

ANDERY, M. A. et al.Para compreender a ciência:uma perspectiva histórica. São Paulo: EDUC, 1988.

ANTUNES, R. Da educação utilitária fordista à da multifuncionalidade liofilizada. Trabalho Encomendado GT11 - Política de Educação Superior. 38 a Reunião Nacional da ANPED. São Luis doMaranhão: UFMA, 2017. Disponível em < http://38reuniao.anped.org.br/programacao/2?field_prog_gt_target_id_entityreference_filter= 14> Acesso em 03/09/2019.

ARAGÃO, M. A. de S. O princípio do poluidor-pagador. Pedra angular da política comunitária do ambiente. São Paulo: Coimbra, 1997. 


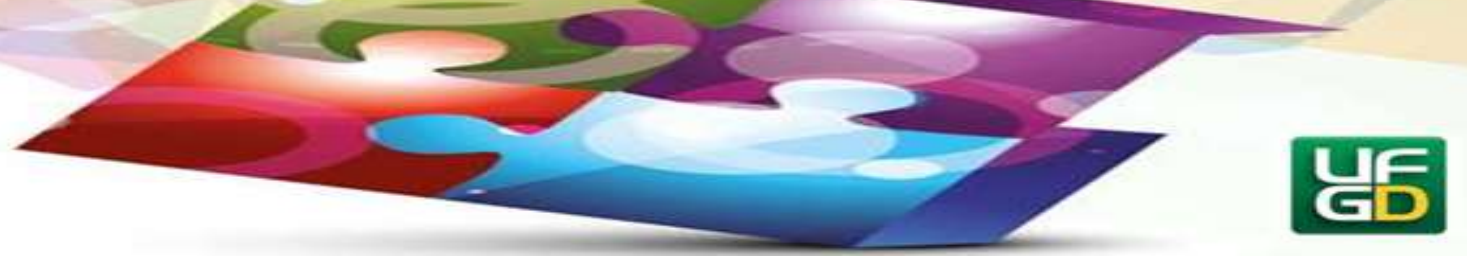

BRASIL. Base Nacional Comum Curricular (BNCC). Educação é a Base. Brasília, MEC/CONSED/UNDIME, 2018. Disponível em:

http://basenacionalcomum.mec.gov.br/images/BNCC_EI_EF_110518_versaofinal_site.pdf. Acesso em 09 de Jun. 2019.

BRASIL. Constituição da República Federativa do Brasil (1988). Promulgada em 05 de outubro de 1988. Disponível em:

http://www.planalto.gov.br/ccivil_03/constituicao/constituicao.htm.

Acesso em: 09 de Jun. 2019.

BRASIL. LeiN 9.394 , de 20 de dezembro de 1996. Disponível em:

http://www.planalto.gov.br/ccivil_03/leis/L9394.htm. Acesso em: 06 de Jun. 2019.

BRASIL. Lei $N^{o} 13.415$, de 16 de fevereiro de 2017.Disponível

em:http://www.planalto.gov.br/ccivil_03/_Ato2015-2018/2017/Lei/L13415.htm. Acesso em: 09 de Jun 2019.

BRASIL. Medida provisória $N^{o} 746$, de 22 de setembro de 2016.

Disponívelem:http://www.planalto.gov.br/ccivil_03/_Ato20152018/2016/Mpv/mpv746.htm. Acesso em: 09 de Jun. 2019.

BRASIL. Parecer CNE/CP $N^{o}:$ 11/2009. Disponível em:

http://portal.mec.gov.br/dmdocuments/parecer_minuta_cne.pdf. Acesso em: 09 de Jun. 2019.

BRASIL. Parecer $n^{o} 1.570$ de 21 de dezembro de 2017. Disponível em:

http://portal.mec.gov.br/docman/dezembro-2017-pdf/78631-pcp015-17-pdf/file. Acesso em: 03 de Jun 2019.

BRASIL. Resolução CNE/CP nº 2, de 22 de dezembro de 2017. Disponível em: http://basenacionalcomum.mec.gov.br/images/historico/RESOLUCAOCNE_CP222DEDEZE MBRODE2017.pdf. Acesso em: 03 de Jun. 2019.

BRASIL. Resolução $n^{o} 3$, de 21 de novembro de 2018. Disponível em: http://portal.mec.gov.br/index.php?option=com_docman\&view=download\&alias=102481rceb003-18\&category_slug=novembro-2018-pdf\&Itemid=30192. Acesso em: 09 de Jun. 2019.

CRISSIUMA, A. L.; ALMEIDA, E. C. P. Experimentação e bem-estar animal - artigo de revisão. Saúde \& Ambiente em Revista, Duque de Caxias, v. 1, n. 2, 2006, p. 1-10.

CURY, C. R. J. As categorias. In: Educação e contradição: elementos metodológicos para uma teoria crítica do fenômeno educativo. 3. ed. São Paulo: Cortez: Autores Associados, 1987.

KNELLER, G. F. A ciência como atividade humana.Rio de Janeiro: Zahar. São Paulo: EDUSP, 1980. 


\section{HORIZONTES - REVISTA DE EDUCACATO}

E-ISSN: 2318-1540

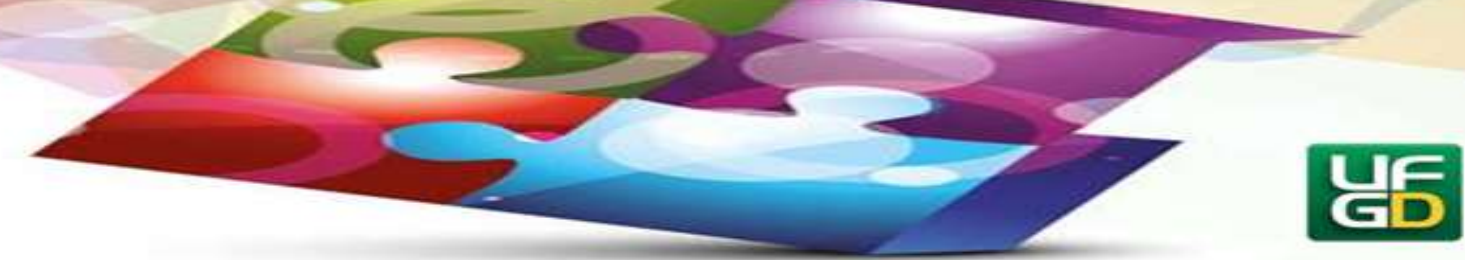

KUENZER, A. Z. Exclusão includente e inclusão excludente: a nova forma de dualidade estrutural que objetiva as novas relações entre educação e trabalho. In: SAVIANI, D.; SANFELICE, J. L.; LOMBARDI, J. C. (Org.). Capitalismo, trabalho e educação. 3. ed. Campinas: Autores Associados, 2005. Acesso em: 3 de Jun 2019.

KUENZER, Acácia Zeneida. Trabalho e escola: a aprendizagem flexibilizada. XI Anped SulReunião Científica Regional da Anped: educação, movimentos sociais e políticas governamentais, UFPR, Curitiba, 24-27 jul. 2016

LOPES, A. C. Parâmetros Curriculares para o Ensino Médio: quando a integração perde seu potencial crítico. In LOPES, A. C. e MACEDO, E. (orgs.) Disciplinas e integração curricular. Rio de Janeiro: DP\&A, 2002.

MARCONDES, M. E. R. As Ciências da Natureza nas $1^{\mathrm{a}}$ e $2^{\mathrm{a}}$ versões da Base Nacional Comum Curricular. Estudos Avançados, v. 32, n. 94, 2018, p. 269-284.

MINISTÉRIO DA EDUCAÇÃO. Secretaria de Educação Básica.Diretrizes Curriculares Nacionais Gerais da Educação Básical Ministério da Educação. Secretária de Educação Básica. Diretoria de Currículos e Educação Integral. Brasília: MEC, SEB, DICEI, 2013. 542p.

PARANÁ. Secretaria de Estado da Educação. Diretrizes Curriculares Estaduais. Curitiba, 2008. Disponível em:

http://www.educadores.diaadia.pr.gov.br/modules/conteudo/conteudo.php?conteudo=1. Acesso em: 06 de Jun. 2019.

SANTOS, B. de. S. Introdução a uma ciência pós moderna. Rio de Janeiro: Graal, 1989.

SAVIANI, D. Pedagogia histórico-crítica. São Paulo: Autores Associados, 2003.

SAVIANI, D. Trabalho e educação: fundamentos ontológicos e históricos. Revista Brasileira de Educação, v. 12, n. 34, jan./abr. 2007, p.152-165. Acesso em: 6 de Jun 2019.

VICENTE, V. R. R. Políticas educacionais para o ensino médio: as implicações da Lei $\mathrm{n}^{\circ}$ 13.415/2017. 243 f. Dissertação (Mestrado em Educação) -2019 . Universidade Estadual de Maringá - UEM.

Enviado: 20/12/2019

Aceito: 09/06/2020 